Antje Wolf und Kerstin Wegener

Flusskreuzfahrten in Deutschland 



\section{Flusskreuzfahrten in Deutschland}

Aktuelle Entwicklungen und Trends

Herausgegeben von

Antje Wolf und Kerstin Wegener 
ISBN 978-3-11-069615-8

e-ISBN (PDF) 978-3-11-069616-5

e-ISBN (EPUB) 978-3-11-069626-4

Library of Congress Control Number: 2021939869

Bibliografische Information der Deutschen Nationalbibliothek

Die Deutsche Nationalbibliothek verzeichnet diese Publikation in der Deutschen Nationalbibliografie; detaillierte bibliografische Daten sind im Internet über http://dnb.dnb.de abrufbar.

(C) 2021 Walter de Gruyter GmbH, Berlin/Boston

Satz: le-tex publishing services $\mathrm{GmbH}$, Leipzig

Druck und Bindung: $\mathrm{CPI}$ books $\mathrm{GmbH}$, Leck

www.degruyter.com 